\title{
The tumour-suppressive function of miR-I and miR-133a targeting TAGLN2 in bladder cancer
}

\author{
H Yoshino', T Chiyomaru*,', H Enokida', K Kawakami', S Tatarano', K Nishiyama', N Nohata ${ }^{2}$, N Seki ${ }^{2}$ \\ and M Nakagawa'
}

'Department of Urology, Graduate School of Medical and Dental Sciences, Kagoshima University, 8-35-I Sakuragaoka, Kagoshima 890-8520, Japan and ${ }^{2}$ Department of Functional Genomics, Graduate School of Medicine, Chiba University, I-8-I Inohana, Chuo-ku, Chiba 260-8670, Japan

BACKGROUND: On the base of the microRNA (miRNA) expression signature of bladder cancer (BC), we found that miR-I and miR-I 33 a were significantly downregulated in BC. In this study, we focussed on the functional significance of miR-I and miR-I33a in $\mathrm{BC}$ cell lines and identified a molecular network of these miRNAs.

METHODS AND RESULTS: We investigated the miRNA expression signature of BC clinical specimens and identified several downregulated miRNAs (miR-133a, miR-204, miR-I, miR-139-5p, and miR-370). MiR-I and miR-I33a showed potential role of tumour suppressors by functional analyses of BC cells such as cell proliferation, apoptosis, migration, and invasion assays. Molecular target searches of these miRNAs showed that transgelin 2 (TAGLN2) was directly regulated by both miR-I and miR- I 33a. Silencing of TAGLN2 study demonstrated significant inhibitions of cell proliferation and increase of apoptosis in BC cell lines. The immunohistochemistry showed a positive correlation between TAGLN2 expression and tumour grade in clinical BC specimens. CONCLUSIONS: The downregulation of miR-I and miR-I33a was a frequent event in BC, and these miRNAs were recognised as tumour suppressive. TAGLN2 may be a target of both miRNAs and had a potential oncogenic function. Therefore, novel molecular networks provided by miRNAs may provide new insights into the underlying molecular mechanisms of BC.

British Journal of Cancer (201 I) 1 04, 808-8I8. doi:I0.1038/bjc.20II.23 www.bjcancer.com

Published online 8 February 201 I

(c) 20II Cancer Research UK

Keywords: TAGLN2; microRNA; miR- /; miR- / 33a; bladder cancer

Bladder cancer (BC) is the fourth most common tumour diagnosed and the second most common cause of death in patients with genitourinary tract malignancies worldwide (Parkin et al, 2005; Jemal et al, 2010). In Japan, the age-standardised mortality rate of $\mathrm{BC}$ has remained relatively stable in men but has increased slightly since 1993 in women (Qiu et al, 2009). There have been significant advances in treatment, including surgical techniques and adjuvant chemotherapy; however, $\mathrm{BC}$ continues to be a common disease with high mortality (Shirodkar and Lokeshwar, 2009). Therefore, new treatment modalities based on novel molecular networks in $\mathrm{BC}$ are desired.

MicroRNAs (miRNAs) are a class of small non-coding RNA molecules of 20-22 nucleotides that have a critical role in a variety of biological processes including development, differentiation, apoptosis, and cell proliferation. They regulate gene expression through translational repression and mRNA degradation. Although their biological functions remain largely unknown, recent studies suggest that miRNAs contribute to the development of various types of cancer (Ryan et al, 2010). A growing body of evidence indicates that miRNAs are aberrantly expressed in many human cancers, and they may function as oncogenes and tumour

*Correspondence: Dr T Chiyomaru;

E-mail: chiyo@m2.kufm.kagoshima-u.ac.jp

Received 22 October 2010 ; revised 6 January 201 I; accepted II January 2011; published online 8 February 2011 suppressors. Upregulated miRNAs could function as oncogenes by negatively regulating tumour-suppressor genes, whereas downregulated miRNAs could act as tumour suppressors, inhibiting cancers by regulating oncogenes (Lu et al, 2005; Calin and Croce, 2006; Ambs et al, 2008; Childs et al, 2009). Bioinformatic predictions indicate that miRNAs regulate $>30 \%$ of the protein coding genes (Filipowicz et al, 2008). It is estimated that $\sim 1000$ miRNAs exist in the vertebrate genome. So far, 1048 human miRNAs are registered at miRBase release 16.0 (http://microrna. sanger.ac.uk/).

$M i R-1$ and $m i R-133 a$ were among the top five downregulated miRNAs in our screening. MiR-1 and miR-133a are muscleenriched miRNAs that inhibit proliferation of progenitor cells and promote myogenesis by targeting histone deacetylase (HDAC4) and serum response factor (SRF), respectively (Chen et al, 2006). Recently, miR-1 and miR-133a have been reported to be downregulated in various cancers and to have tumour-suppressive functions (Datta et al, 2008; Nasser et al, 2008; Yan et al, 2009; Uchida et al, 2010; Chiyomaru et al, 2010a). We have reported that miR-133a directly regulated oncogenic FSCN1, LASP1, and GSTP1 genes in human BC (Uchida et al, 2010; Chiyomaru et al, 2010a, b). We recognised that $m i R-1$ and $m i R-133 a$ are located on the same chromosomal loci (18q11.2 and 20q13.33) (Chiyomaru et al, 2010b). Like this, several miRNAs are located on the same chromosomal region, in a so-called 'cluster'. Recent studies demonstrated that $m i R-17-92$ cluster and $m i R-221 / 222$ cluster, which harbour oncogenic miRNAs, had important roles in several 
human malignancies (Zhang et al, 2009; Di Leva et al, 2010). However, the functional roles of the target genes regulated by these miRNA clusters have not been thoroughly investigated.

The aim of this study was to investigate whether miR-1 has tumour-suppressive function in $\mathrm{BC}$ cell lines and to find common target genes of miR-1 and miR-133a. We focussed on transgelin 2 (TAGLN2), which was one of the most downregulated genes in oligo-microarray studies using an $m i R-1$ transfectant and is a putative target gene of $m i R-1$ and $m i R-133 a$ as suggested by webbased software. The functional role of TAGLN2 has not yet been determined. Previous studies have reported that high expressions of TAGLN2 were observed in various human malignancies (Chen et al, 2005; Shi et al, 2005; Huang et al, 2006; Rho et al, 2009; Zhang et al, 2010). We hypothesised that $m i R-1$ and $m i R-133 a$ directly regulate TAGLN2, which may have an oncogenic function in BC. We performed a luciferase reporter assay to determine whether TAGLN2 mRNA is actually targeted by $m i R-1$ and $m i R-133 a$ and a loss-of-function study using $\mathrm{BC}$ cell lines to investigate the functional roles of TAGLN2 in BC.

\section{MATERIALS AND METHODS}

\section{Clinical specimens and cell culture}

Tissue specimens for miRNA screening using a low-density array (LDA) were from $11 \mathrm{BC}$ patients who had undergone cystectomy or transurethral resection of bladder tumours (TUR-BT) at Kagoshima University Hospital between 2007 and 2008. The tissue specimens for quantitative RT - PCR were from $23 \mathrm{BC}$ patients who had received cystectomy or TUR-BT at Kagoshima University Hospital between 2006 and 2009. The patients' backgrounds and clinicopathological characteristics are summarised in Supplementary Table 1. Normal bladder epitheliums (NBEs) were derived from patients with noncancerous disease. These specimens were staged according to the American Joint Committee on Cancer/ Union Internationale Contre le Cancer tumour-node-metastasis classification and histologically graded (Sobin and Wittekind, 2002). Our study was approved by the Bioethics Committee of Kagoshima University; written previous informed consent and approval were given by these patients.

We used two human BC cell lines: BOY, which was established in our laboratory from an Asian male patient aged 66 years who was diagnosed with stage III BC with lung metastasis; and T24, which was invasive and obtained from the American Type Culture Collection. These cell lines were maintained in a minimum essential medium (MEM) supplemented with $10 \%$ fetal bovine serum in a humidified atmosphere of $5 \% \mathrm{CO}_{2}$ and $95 \%$ air at $37^{\circ} \mathrm{C}$.

\section{Tissue collection and RNA extraction}

Tissues were immersed in RNAlater (QIAGEN, Valencia, CA, USA) and stored at $-20{ }^{\circ} \mathrm{C}$ until the RNA extraction. Total RNA including miRNA was extracted using the mirVana miRNA isolation kit (Ambion, Austin, TX, USA) following the manufacturer's protocol. The integrity of the RNA was checked with RNA 6000 Nano Assay Kit and a 2100 Bioanalyzer (Agilent Technologies, Santa Clara, CA, USA).

\section{MiRNA expression signatures and data normalisation}

MicroRNA expression patterns were evaluated using the TaqMan LDA Human microRNA Panel v2.0 (Applied Biosystems, Foster City, CA, USA). The assay was composed of two steps: generation of cDNA by reverse transcription and a TaqMan real-time PCR assay. The description of real-time PCR and the list of human miRNAs can be found on the company's website (http://www. appliedbiosystems.com). An analysis of relative miRNA expression data was performed using GeneSpring GX version 7.3.1 software
(Agilent Technologies) according to the manufacturer's instructions. A cutoff $P$-value of $<0.05$ was used to narrow down the candidates after global normalisation of the raw data. After global normalisation, additional normalisation was done by RNU48 and MammU6.

\section{Quantitative real-time RT - PCR}

TaqMan probes and primers for TAGLN2 (P/N: Hs00761239_m1; Applied Biosystems) were assay-on-demand gene expression products. All reactions were performed in duplicate and a negative control lacking cDNA was included. We followed the manufacturer's protocol for PCR conditions. Stem-loop RT - PCR (TaqMan MicroRNA Assays; P/N: PM10617 for miR-1, and PM10413 for miR-133a; Applied Biosystems) was used to quantitate miRNAs according to the earlier published conditions (Ichimi et al, 2009). To normalise the data for quantification of TAGLN2 mRNA and the miRNAs, we used human GUSB (P/N: Hs99999908_m1; Applied Biosystems) and RNU48 (P/N: 001006; Applied Biosystems), respectively, and the $\Delta \Delta \mathrm{Ct}$ method was employed to calculate the fold change. As a control RNA, we used Premium Total RNA from normal human bladder (AM7990; Applied Biosystems).

\section{Mature miRNA and siRNA transfection}

As described elsewhere (Ichimi et al, 2009), the BC cell lines were transfected with Lipofectamine RNAiMAX transfection reagent (Invitrogen, Carlsbad, CA, USA) and Opti-MEM (Invitrogen) with $10 \mathrm{~nm}$ of mature miRNA molecules. Pre-miR and negative-control miRNA (Applied Biosystems) were used in the gain-of-function experiments, whereas TAGLN2 siRNA (Cat no. HSS144745 and HSS144746; Invitrogen) and negative-control siRNA (D-001810-10; Thermo Fisher Scientific, Waltham, MA, USA) were used in the loss-of-function experiments. Cells were seeded in a $10-\mathrm{cm}$ dish for protein extraction $\left(8 \times 10^{5}\right.$ per dish), in a six-well plate for apoptosis $\left(10 \times 10^{4}\right.$ per well) and for wound healing assay $\left(20 \times 10^{4}\right.$ per well), in a 24 -well plate for mRNA extraction and luciferase reporter assay $\left(5 \times 10^{4}\right.$ per well), and in a 96 -well plate for XTT assay (3000 per well).

\section{Cell proliferation, migration, and invasion assays}

Cell proliferation was determined using an XTT assay (Roche Applied Sciences, Tokyo, Japan) performed according to the manufacturer's instructions. Cell migration activity was evaluated by wound healing assay. Cells were plated in six-well dishes, and the cell monolayer was scraped using a P-20 micropipette tip. The initial gap length $(0 \mathrm{~h})$ and the residual gap length $24 \mathrm{~h}$ after wounding were calculated from photomicrographs. A cell invasion assay was carried out using modified Boyden Chambers consisting of transwell-precoated matrigel membrane filter inserts with $8-\mathrm{mm}$ pores in 24-well tissue culture plates (BD Biosciences, Bedfold, MA, USA). Minimum essential medium containing $10 \%$ fetal bovine serum in the lower chamber served as the chemoattractant as described previously (Chiyomaru et al, 2010a). All experiments were performed in triplicate.

\section{Apoptosis analysis}

The $\mathrm{BC}$ cell lines transiently transfected with transfection reagent only (mock), si-control, si-TAGLN2, miR-control, miR-1, or $m i R-133 a$ in six-well tissue culture plates as described earlier were harvested $72 \mathrm{~h}$ after transfection by trypsinisation and washed in cold PBS. Double staining with FITC-Annexin V and propidium iodide (PI) was carried out using the FITC Annexin V Apoptosis Detection Kit (BD Biosciences) according to the manufacturer's recommendations and immediately analysed within an hour by flow cytometry (FACScan; BD Biosciences). Cells were discriminated 
into viable cells, dead cells, early apoptotic cells, and apoptotic cells by the CellQuest software (BD Biosciences), and then the percentages of early apoptotic and apoptotic cells from each experiment were compared. Experiments were done in triplicate.

\section{Target gene search for $m i R-1$}

Oligo-microarray Human 44K (Agilent) was used for expression profiling in miR-1-transfected BC cell lines (BOY and T24) in comparison with miR-negative control transfectant, as previously described (Chiyomaru et al, 2010a). Briefly, hybridisation and washing steps were performed in accordance with the manufacturer's instructions. The arrays were scanned using a Packard GSI Lumonics ScanArray 4000 (PerkinElmer, Boston, MA, USA). The data obtained were analysed with DNASIS array software (Hitachi Software Engineering, Tokyo, Japan), which converted the signal intensity for each spot into text format. The Log2 ratios of the median subtracted background intensity were analysed. Data from each microarray study were normalised by global normalisation.

The predicted target genes and their miRNA binding site seed regions were investigated using TargetScan (release 5.1, http:// www.targetscan.org/). The sequences of the predicted mature miRNAs were confirmed using miRBase (release 16.0, September 2010; http://microrna.sanger.ac.uk/).

\section{Western blots}

After 3 days of transfection, protein lysate $(20 \mu \mathrm{g})$ was separated by NuPAGE on $4-12 \%$ bis-tris gel (Invitrogen) and transferred into a polyvinylidene fluoride membrane. Immunoblotting was done with diluted $(1: 150)$ polyclonal TAGLN2 antibody (HPA001925; Sigma-Aldrich, St Louis, MO, USA) and GAPDH antibody (MAB374; Chemicon, Temecula, CA, USA). The membrane was washed and then incubated with goat anti-rabbit IgG $(\mathrm{H}+\mathrm{L})-\mathrm{HRP}$ conjugate (Bio-Rad, Hercules, CA, USA). Specific complexes were visualised with an echochemiluminescence (ECL) detection system (GE Healthcare, Little Chalfont, UK), and the expression level of these genes was evaluated using ImageJ software (ver. 1.43; http:// rsbweb.nih.gov/ij/index.html).

\section{Plasmid construction and dual-luciferase reporter assay}

The miRNA target sequences were inserted between the XhoIPmeI restriction sites in the $3^{\prime} \mathrm{UTR}$ of the $h R l u c$ gene in the psiCHECK-2 vector (C8021; Promega, Madison, WI, USA). Primer sequences for full-length $3^{\prime} \mathrm{UTR}$ of TAGLN2 mRNA (5'-ATCGCTC GAGACAGATGGGCACCAACCGCG- $3^{\prime}$ and $5^{\prime}$-CTCTAGGTTTAAA CATCTTCCTCAAGCCCCAGAC- $3^{\prime}$ ) were designed. Specific miRNA target sequences (40 bp length, Supplementary Table 2) for $m i R-1$ and miR-133a were artificially synthesised and inserted in the vector. Following that, T24 cells were transfected with $15 \mathrm{ng}$ of vector, $10 \mathrm{~nm}$ of miRNA, and $1 \mu \mathrm{l}$ of Lipofectamine 2000 (Invitrogen) in $100 \mu \mathrm{l}$ of Opti-MEM (Invitrogen). The activities of firefly and Renilla luciferases in cell lysates were determined with a dual-luciferase assay system (E1910; Promega). Normalised data were calculated as the quotient of Renilla/firefly luciferase activities.

\section{Immunohistochemistry}

A tissue microarray of 47 urothelial carcinomas and 8 normal bladders was obtained from US Biomax, Inc. (BL208; Rockville, MD, USA). Detailed information on all tumour specimens can be found at http://www.biomax.us/index.php. Immunostaining was done on the tissue microarray following the manufacturer's protocol. The primary rabbit polyclonal antibodies against TAGLN2 (Sigma-Aldrich) were diluted by $1: 25$. The slides were treated with biotinylated anti-rabbit IgG $(\mathrm{H}+\mathrm{L})$ made in goat (Vector Laboratories, Burlingame, CA, USA). Diaminobenzidinehydrogen peroxide (Sigma-Aldrich) was the chromogen, and the counterstaining was done with $0.5 \%$ haematoxylin. The positivity of endothelia served as an inner positive control. Immunostaining was evaluated according to a scoring method as described previously (Zhang et al, 2010). Each case was scored on the basis of the intensity and area of staining. The intensity of staining was graded on the following scale: 0 , no staining; $1+$, mild staining; $2+$, moderate staining; and $3+$, intense staining. The area of staining was evaluated as follows: 0 , no staining of cells in any microscopic fields; $1+,<30 \%$ of cells stained positive; $2+, 30-60 \%$ stained positive; and $3+,>60 \%$ stained positive. A combined staining score (intensity + extension) of $\leqslant 2$ was low expression, a score between 3 and 4 was moderate expression, and a score between 5 and 6 was high expression.

\section{Statistical analysis}

The relationship between two variables and the numerical values obtained by real-time RT-PCR was analysed using the MannWhitney $U$-test. The relationship among three variables and the numerical values was analysed using the Bonferroni-adjusted Mann-Whitney $U$-test. The $\chi^{2}$-test was used to evaluate the relationships between the immunohistochemical score of TAGLN2 expression and clinicopathological factors. Expert StatView analysis software (version 4; SAS Institute Inc., Cary, NC, USA) was used in both cases. In the comparison among three variables, a nonadjusted statistical level of significance of $P<0.05$ corresponds to a Bonferroni-adjusted level of $P<0.0167$.

\section{RESULTS}

\section{Identification of downregulated miRNAs in BC by miRNA expression signatures}

We evaluated mature miRNA expression levels of $11 \mathrm{BC}$ and $5 \mathrm{NBE}$ specimens by miRNA expression signatures. A total of 41 and 19 downregulated miRNAs were selected after the normalisation using RNU48 and MammU6, respectively (Supplementary Tables 3 and 4). The 17 miRNAs were commonly downregulated with RNU48 and MammU6 normalisation (Table 1). The top five miRNAs ( $m i R-133 a, m i R-204, m i R-1, m i R-139-5 p$, and $m i R-370)$ in the list were subjected to further study.

Table I Downregulated microRNAs in bladder cancer (BC)

\begin{tabular}{lcccc}
\hline microRNA & P-value & Normal & Cancer & $\begin{array}{c}\text { Fold change } \\
\text { Cancer/normal }\end{array}$ \\
\hline hsa-miR-133a & $3.50 \mathrm{E}-02$ & $1.17 \mathrm{E}-0 \mathrm{I}$ & $2.48 \mathrm{E}-03$ & $2.12 \mathrm{E}-02$ \\
hsa-miR-204 & $4.50 \mathrm{E}-02$ & $4.5 \mathrm{IE}-03$ & $2.08 \mathrm{E}-04$ & $4.61 \mathrm{E}-02$ \\
hsa-miR-1 & $9.40 \mathrm{E}-03$ & $1.52 \mathrm{E}-03$ & $7.16 \mathrm{E}-05$ & $4.72 \mathrm{E}-02$ \\
hsa-miR-139-5p & $1.71 \mathrm{E}-04$ & $8.31 \mathrm{E}-02$ & $4.65 \mathrm{E}-03$ & $5.60 \mathrm{E}-02$ \\
hsa-miR-370 & $2.37 \mathrm{E}-02$ & $8.95 \mathrm{E}-04$ & $8.26 \mathrm{E}-05$ & $9.23 \mathrm{E}-02$ \\
hsa-miR-133b & $3.60 \mathrm{E}-02$ & $1.78 \mathrm{E}-03$ & $1.26 \mathrm{E}-04$ & $7.06 \mathrm{E}-02$ \\
hsa-miR-574-3p & $6.11 \mathrm{E}-04$ & $3.25 \mathrm{E}-01$ & $3.63 \mathrm{E}-02$ & $1.12 \mathrm{E}-01$ \\
hsa-miR-376c & $2.57 \mathrm{E}-03$ & $1.44 \mathrm{E}-02$ & $1.91 \mathrm{E}-03$ & $1.32 \mathrm{E}-01$ \\
hsa-miR-214 & $2.62 \mathrm{E}-03$ & $5.08 \mathrm{E}-02$ & $7.29 \mathrm{E}-03$ & $1.43 \mathrm{E}-01$ \\
hsa-let-7c & $1.34 \mathrm{E}-03$ & $4.70 \mathrm{E}-03$ & $7.16 \mathrm{E}-04$ & $1.52 \mathrm{E}-01$ \\
hsa-miR-140-3p & $6.29 \mathrm{E}-03$ & $1.73 \mathrm{E}-02$ & $2.96 \mathrm{E}-03$ & $1.72 \mathrm{E}-01$ \\
hsa-miR-134 & $7.02 \mathrm{E}-04$ & $3.54 \mathrm{E}-03$ & $6.69 \mathrm{E}-04$ & $1.89 \mathrm{E}-01$ \\
hsa-miR-4II & $1.43 \mathrm{E}-03$ & $4.58 \mathrm{E}-03$ & $1.05 \mathrm{E}-03$ & $2.29 \mathrm{E}-01$ \\
hsa-miR-218 & $1.83 \mathrm{E}-03$ & $1.66 \mathrm{E}-02$ & $4.06 \mathrm{E}-03$ & $2.44 \mathrm{E}-01$ \\
hsa-miR-196b & $6.14 \mathrm{E}-03$ & $2.76 \mathrm{E}-02$ & $7.56 \mathrm{E}-03$ & $2.74 \mathrm{E}-01$ \\
hsa-miR-186 & $8.04 \mathrm{E}-04$ & $8.68 \mathrm{E}-02$ & $3.10 \mathrm{E}-02$ & $3.57 \mathrm{E}-01$ \\
hsa-miR-320 & $3.81 \mathrm{E}-02$ & $2.34 \mathrm{E}-01$ & $9.70 \mathrm{E}-02$ & $4.14 \mathrm{E}-01$ \\
\hline
\end{tabular}


Detection of $m i R-133 a, m i R-204, m i R-1, m i R-139-5 p$, and miR-370 expression by quantitative stem-loop RT - PCR

Quantitative stem-loop RT-PCR demonstrated that the expression levels of the top five miRNAs (miR-133a, miR-204, $m i R-1$, $m i R-139-5 p$, and $m i R-370)$ were significantly lower in $23 \mathrm{BC}$ specimens in comparison with 10 NBEs $(P<0.005$; Figure 1$)$. These miRNA expressions were significantly lower in BC cell lines (BOY and T24) in comparison with the normal human bladder RNA $(P<0.0001$; Figure $2 \mathrm{~A})$.

Effect of the downregulated miRNA transfection on cell proliferation, migration activity, and invasion in $\mathrm{BC}$ cell lines

To investigate the functional role of the five selected miRNAs, we performed gain-of-function studies using the miRNA transfectants. The XTT assay showed significant cell proliferation inhibitions in $m i R-1$ and $m i R-133 a$ transfectants in comparison with the miR-control transfectants (percentage of cell viability for BOY: $59.9 \pm 1.4,64.1 \pm 1.4$, and $100.0 \pm 1.2$, respectively, $P<0.0001$; and for T24: $43.3 \pm 0.6,62.4 \pm 0.7$, and $100.0 \pm 0.7$, respectively, $P<0.0001$ ), but no significant inhibition was observed in other miRNA transfectants except the miR-204-transfected BOY cell line (Figure 2B). The wound healing assay showed significant cell migration inhibitions in $m i R-1$ and $m i R-133 a$ transfectants in comparison with the controls (percentage of wound closure for BOY; $41.4 \pm 2.5,71.3 \pm 4.4$, and $100.0 \pm 3.2$, respectively, $P<0.0001$; and for T24: $26.0 \pm 2.4,65.2 \pm 3.9$, and $100.0 \pm 3.2$, respectively, $P<0.0001$ ), but no significant inhibition was observed in other miRNA transfectants except $m i R$-370-transfected BOY cell line (Figure 2C). Matrigel invasion assay demonstrated that invading cell numbers were significantly decreased in both $m i R-1$ - and $m i R-133 a$-transfected BOY cell lines and miR-1-transfected T24 cell line in comparison with the controls (percentage of cell invasion for BOY: $23.4 \pm 3.0,57.3 \pm 8.9$, and $100.0 \pm 10.0$, respectively, $P<0.0001$; and for T24: $43.4 \pm 4.8,96.5 \pm 4.4$, and $100.0 \pm 3.8$, respectively, $P<0.0001$; the $m i R-1$ transfectant $v s$ control), but no significant inhibition was observed in other miRNA transfectants except the miR-370-transfected BOY cell line (Figure 2D). To evaluate the simultaneous effect of miR-1 and miR-133a, we evaluated another XTT assay by using $m i R-1$ and $m i R-133 a$ co-transfected BOY and T24 cell lines. We found similar effects of cell viability inhibition by the transfectants in comparison with that of each miR-1 or miR-133a transfectants (Supplementary Figure 1). Because $m i R-1$ and $m i R-133 a$ transfection had a

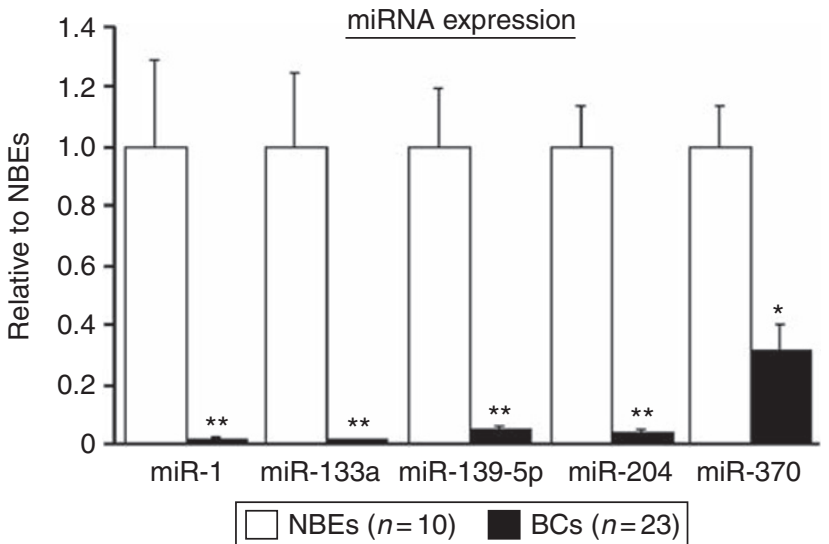

Figure I MicroRNA expression levels in clinical specimens. Real-time RT-PCR showed that miRNA expression in BCs was lower than that of NBEs. $* P<0.005 ; * * P<0.0001$.
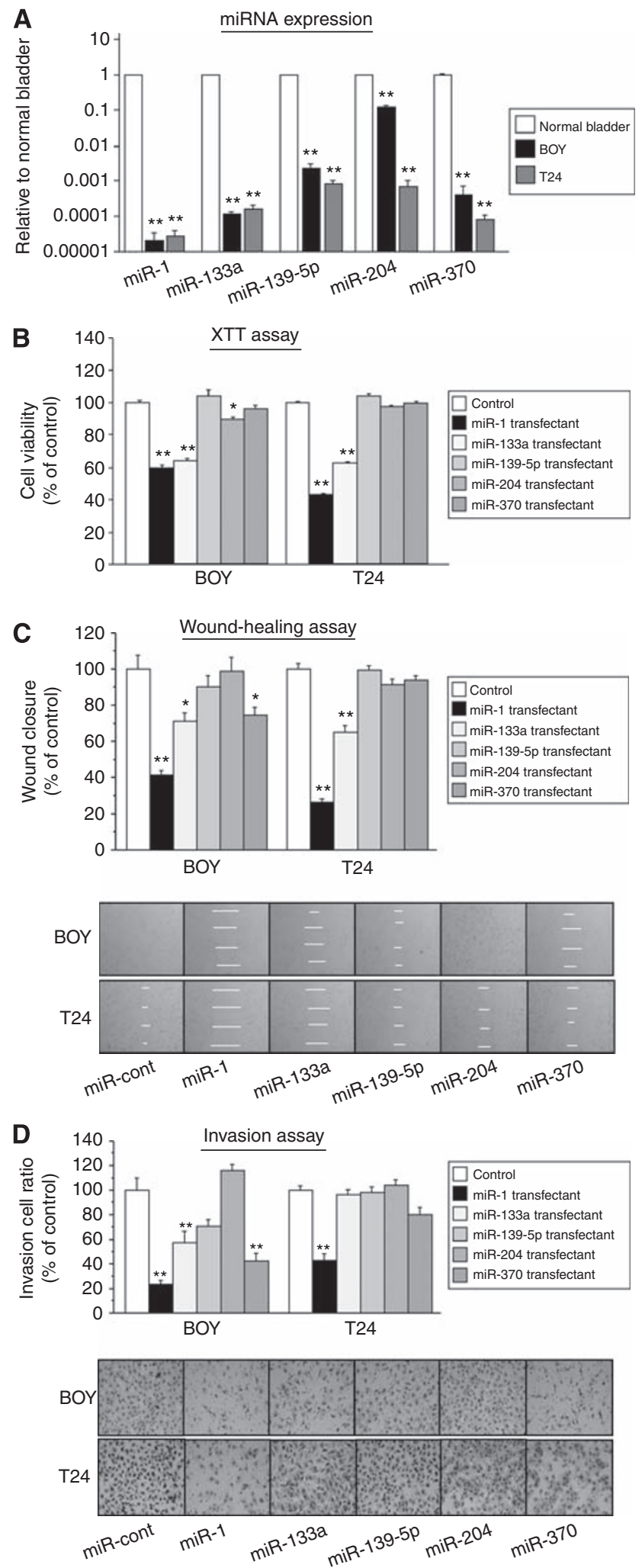

Figure 2 (A) MicroRNA expression levels in BC cell lines. Real-time RT-PCR showed that miRNA expression in BC cell lines (BOY and T24) was lower than that of the normal human bladder RNA. (B-D) Effect of cell viabilities in miRNA (miR-I, miR-133a, miR-139-5p, miR-204, and miR-370) transfectants: (B) cell proliferation determined by the XTT assay; (C) cell migration activity determined by the wound healing assay; and (D) cell invasion activity determined by the matrigel invasion assay in $\mathrm{BOY}$ and $\mathrm{T} 24$ cell lines transfected with the miRNAs. $* P<0.005$; $* * P<0.0001$. 
A

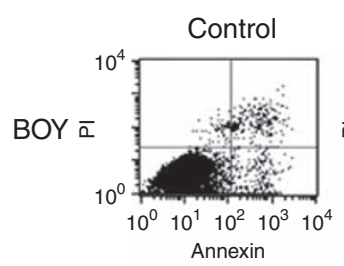

T24 무

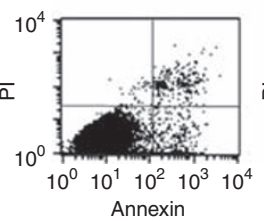

$\operatorname{miR}-1$

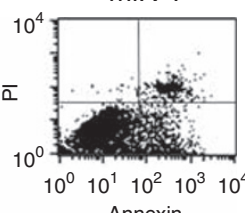

Annexin

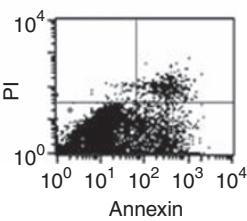

B

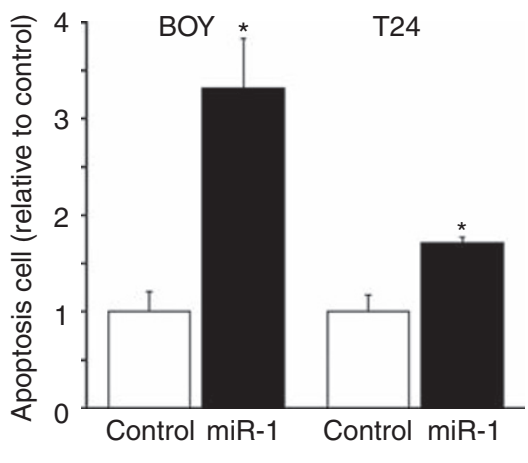

Figure 3 (A) Apoptosis assay determined by flow cytometry. Early apoptotic cells can be seen in the bottom right quadrant and late are in the upper right. (B) The normalised ratio of the apoptosis assay is shown in the histogram. $* P<0.05$.

Table 2 Downregulated genes in miR-I transfectants

\begin{tabular}{|c|c|c|c|c|c|c|}
\hline \multirow[b]{2}{*}{ Entrez gene ID } & \multirow[b]{2}{*}{ Symbol } & \multicolumn{3}{|c|}{ Fold change (log 2 ratio) } & \multirow[b]{2}{*}{ Description } & \multirow[b]{2}{*}{ Target sites } \\
\hline & & BOY & T24 & Average & & \\
\hline 23446 & SLC44AI & -3.86 & -3.69 & -3.77 & Solute carrier family 44, member 1 & + \\
\hline | | 4902 & CIQTNF5 & -3.92 & -3.48 & -3.70 & $\mathrm{Clq}$ and tumour necrosis factor related protein 5 & - \\
\hline 8407 & TAGLN2 & -3.67 & -3.33 & -3.50 & Transgelin 2 & + \\
\hline 27230 & SERPI & -3.14 & -3.45 & -3.30 & Stress-associated endoplasmic reticulum protein I & + \\
\hline 359845 & FAMIOIB & -3.35 & -2.87 & -3.11 & Family with sequence similarity 101 , member B & + \\
\hline 5756 & TWFI & -3.03 & -2.84 & -2.93 & Twinfilin, actin-binding protein, homologue I (Drosophila) & + \\
\hline 79794 & Cl2orf49 & -3.04 & -2.69 & -2.86 & Chromosome 12 open reading frame 49 & + \\
\hline 2697 & G/AI & -2.17 & -3.07 & -2.62 & Gap junction protein, $\alpha$ l, $43 \mathrm{kDa}$ & + \\
\hline 4860 & PNP & -2.65 & -2.54 & -2.60 & Purine nucleoside phosphorylase & + \\
\hline 57580 & PREXI & -2.07 & -2.44 & -2.26 & Phosphatidylinositol-3,4,5-trisphosphate-dependent Rac exchange factor I & + \\
\hline 8683 & SFRS9 & -2.33 & -2.14 & -2.24 & Splicing factor, arginine/serine-rich 9 & + \\
\hline 23531 & $M M D$ & -2.37 & -2.08 & -2.22 & Monocyte to macrophage differentiation-associated & + \\
\hline 2539 & G6PD & -2.31 & -2.06 & -2.18 & Glucose-6-phosphate dehydrogenase & + \\
\hline 84912 & SLC35B4 & -2.31 & -2.05 & -2.18 & Solute carrier family 35 , member B4 & + \\
\hline 7117 & TMSL3 & -2.06 & -2.30 & -2.18 & Thymosin-like 3 & + \\
\hline 10487 & CAPI & -2.25 & -2.08 & -2.17 & CAP, adenylate cyclase-associated protein I (yeast) & + \\
\hline 5757 & PTMA & -2.25 & -2.04 & -2.15 & Prothymosin, $\alpha$ & + \\
\hline 378 & ARF4 & -2.12 & -2.14 & -2.13 & ADP-ribosylation factor 4 & + \\
\hline
\end{tabular}

significantly stronger tumour-suppressive effect among the five miRNAs, they were subjected to further analyses as the leading candidates for tumour-suppressive miRNAs in BC.

\section{MiR-1 induced apoptosis in BC cell lines}

Cell apoptosis in miR-1 transfectants was detected using flow cytometry. As shown by representative images in Figure $3 \mathrm{~A}$, the apoptotic cell fractions (early apoptotic and apoptotic; lower right and upper right, respectively) were greater in $m i R-1$ transfectants than in miR-control transfectants (BOY and T24). As shown in Figure $3 \mathrm{~B}, m i R-1$ transfection induced apoptosis in $\mathrm{BC}$ cell lines (BOY, $3.31 \pm 0.51$ and $1.00 \pm 0.20$; T24, $1.70 \pm 0.08$ and $1.00 \pm 0.17$, respectively, $P<0.05)$. In terms of $m i R-133 a$, we previously demonstrated that $m i R-133 a$ transfection also induced apoptosis in the same BC cell lines (Uchida et al, 2010).

\section{Gene expression profile identifying downregulated genes in $m i R-1$ transfectant}

To gain further insight into which genes are affected by $m i R-1$ transfection, we performed gene expression analysis with $m i R-1$ transfectants and the controls (BOY and T24 cells). A total of
18 genes were downregulated less than -4.0 -fold in $m i R-1$ transfectants compared with the controls (Table 2). The TargetScan program showed that 17 genes had putative target sites of $m i R$ 1 in their $3^{\prime}$ UTR (Table 2). Previously, we had performed gene expression analysis with miR-133a transfectants (Uchida et al, 2010), and the TAGLN2 gene was commonly listed in the top 10 downregulated genes in current $(m i R-1)$ and former $(m i R-133 a)$ signatures. Therefore, we focussed on the TAGLN2 gene as a promising candidate targeted by both $m i R-1$ and $m i R-133 a$. Entries from the former and the current microarray data were approved by the Gene Expression Omnibus (GEO) and were assigned GEO accession numbers GSE19717 and GSE24782.

\section{TAGLN2 expression in BC cell lines and TAGLN2 silencing by $m i R-1$ and $m i R-133 a$ transfection}

The quantitative real-time RT-PCR analysis showed that the mRNA expression of TAGLN2 in the BOY and T24 cell lines was more than two-fold higher than that in the normal human bladder RNA (Figure 4A). To examine the functional role of TAGLN2, we performed gain-of-function studies using $m i R-1$ and miR-133a transfectant (BOY and T24) cell lines, and the mRNA and protein expression levels of TAGLN2 were markedly 
A

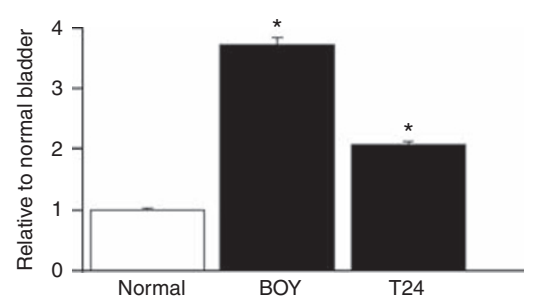

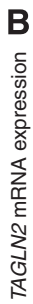
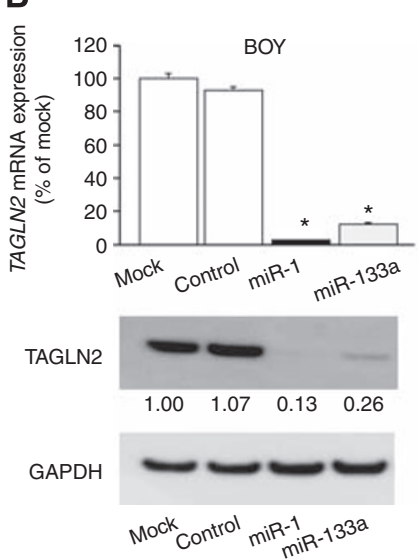
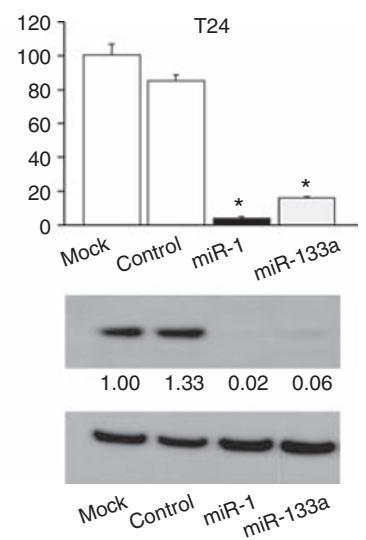

Figure 4 (A) The mRNA expression of TAGLN2 in the BOY and T24 cell lines and the normal human bladder RNA. The mRNA expression of TAGLN2 was more than two-fold in BC cell lines compared with the normal human bladder RNA. (B, upper) TAGLN2 mRNA expression after $24 \mathrm{~h}$ of transfection with $10 \mathrm{~nm}$ of the miRNA (miR-I and miR-/33a). (B, lower) TAGLN2 protein expression after $72 \mathrm{~h}$ of transfection of miRNA. GAPDH was used as a loading control. The protein expression level of TAGLN2 was also repressed in the transfectants.

miR-I and miR-I33a as tumour suppressors in BC

$\mathrm{H}$ Yoshino et al

downregulated in the transfectants in comparison with the controls (Figure 4B).

\section{TAGLN2 as a target of post-transcriptional repression by} $m i R-1$ and $m i R-133 a$

We performed a luciferase reporter assay to determine whether TAGLN2 mRNA has a target site for $m i R-1$ and $m i R-133 a$. We used a vector encoding full-length $3^{\prime} \mathrm{UTR}$ of TAGLN2 mRNA and found that the luminescence intensity was significantly reduced in the $m i R-1$ and $m i R-133 a$ transfectant (Figure 5A). Furthermore, the luminescence intensity significantly decreased at the three sites targeted by miR-1 (position 71-77, 185-191, and 348-354) and two sites targeted by miR-133a (position $214-220$ and 242-248) (Figure 5B).

\section{Effect of TAGLN2 knockdown on cell proliferation, invasion, and migration activity in $\mathrm{BC}$ cell lines}

To examine the functional role of TAGLN2, we performed loss-offunction studies using two different si-TAGLN2 transfections into BOY and T24 cell lines. The mRNA and protein expression of TAGLN2 was markedly repressed by these si-TAGLN2 transfections (Figure 6A). The XTT assay revealed significant cell proliferation inhibition in the two si-TAGLN2 transfectants in comparison with that in the untransfectants (mock) and the si-control transfectants (percentage of cell viability for BOY: $69.0 \pm 1.3,49.7 \pm 2.0, \quad 100.0 \pm 2.6$, and $104.6 \pm 2.9$, respectively, $P<0.0001$; and for T24: $77.4 \pm 1.4,63.6 \pm 1.4,100.0 \pm 1.2$, and $100.5 \pm 1.6$, respectively, $P<0.0001$; Figure $6 \mathrm{~B})$. The wound healing assay also demonstrated significant cell migration inhibitions in the two si-TAGLN2 transfectants compared with the counterparts (percentage of wound closure for BOY: $36.0 \pm 7.3,15.8 \pm 11.4$, $100.0 \pm 3.0$, and $98.2 \pm 2.6$, respectively, $P<0.0001$; and for T24: $79.3 \pm 2.6,43.6 \pm 3.2, \quad 100.0 \pm 2.3$, and $104.3 \pm 2.3$, respectively,

A

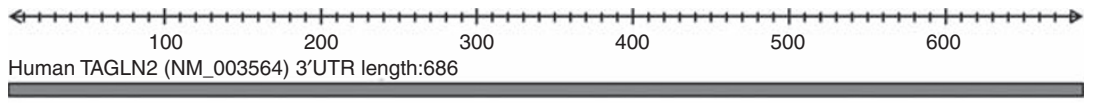
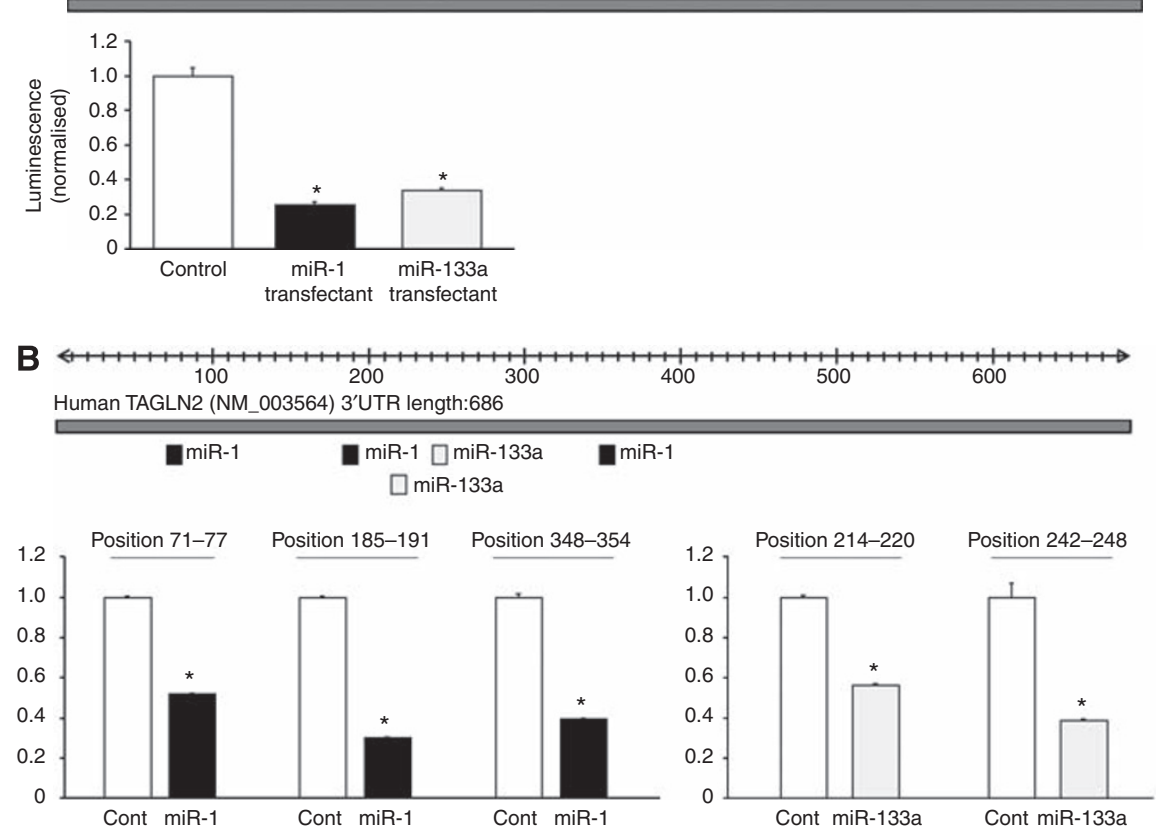

Figure 5 MiR-I and miR-I 33a binding sites in 3'-UTR of TAGLN2 mRNA. (A) A luciferase reporter assay using the vector encoding full-length 3'-UTR of TAGLN2 mRNA. The Renilla luciferase values were normalised by firefly luciferase values. (B) Luciferase reporter assays using the vectors encoding putative target sites of TAGLN2 3'-UTR: three target sites for miR-I and two sites for miR-I33a. 
$P<0.0001$; Figure 6C). The matrigel invasion assay demonstrated that the number of invading cells was significantly decreased in the two si-TAGLN2 transfectants compared with the counterparts (percentage of cell invasion for BOY: $49.2 \pm 3.3,6.2 \pm 2.7$, $100.0 \pm 12.8$, and $97.7 \pm 10.7$, respectively, $P<0.0005$; and for T24: $45.7 \pm 4.0,53.2 \pm 5.3, \quad 100.0 \pm 6.0$, and $108.3 \pm 7.6$, respectively, $P<0.0001$; Figure 6D).

\section{TAGLN2 knockdown-induced apoptosis in BC cell lines}

The apoptotic cell fractions were greater in the two si-TAGLN2 transfectants than those in the mock and si-control transfectant at $72 \mathrm{~h}$ after transfection (relative to mock; BOY: 2.34 \pm 0.04 ,
$2.84 \pm 0.05,1.00 \pm 0.15$, and $1.00 \pm 0.15$, respectively, $P<0.0001$ T24: $1.93 \pm 0.09,2.70 \pm 0.12,1.00 \pm 0.00$, and $1.18 \pm 0.07$, respectively, $P<0.0001$; Figure $6 \mathrm{E}$ ).

\section{Immunohistochemistry of TAGLN2 in tissue microarray}

Figure 7 shows representative results of immmunohistochemical staining of TAGLN2. The TAGLN2 was strongly expressed in several tumour lesions: A (Grade 1, T2bN0M0), B (Grade 2, T3N0M0), C (Grade 3, T2N0M0), and D (Grade 3, metastatic region), whereas no expression was observed in the normal tissue (E); the expression score of tumours was significantly higher than that of normal tissues $(P=0.0202)$. We found that there were
A

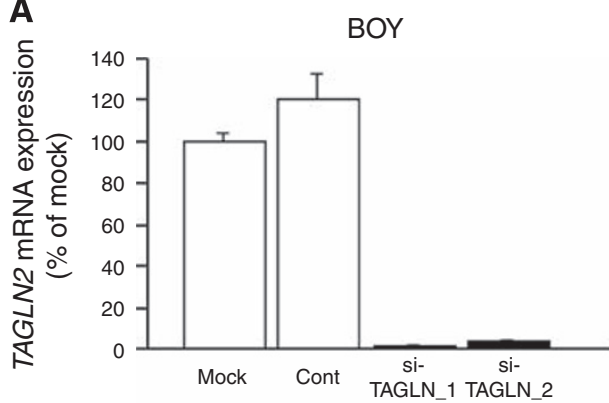

TAGLN2

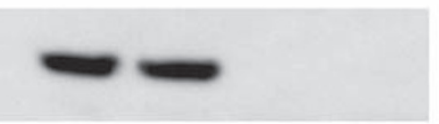

GAPDH

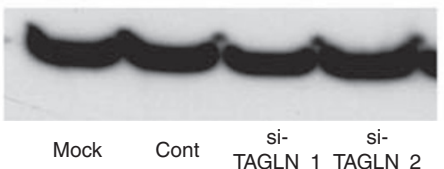

T24
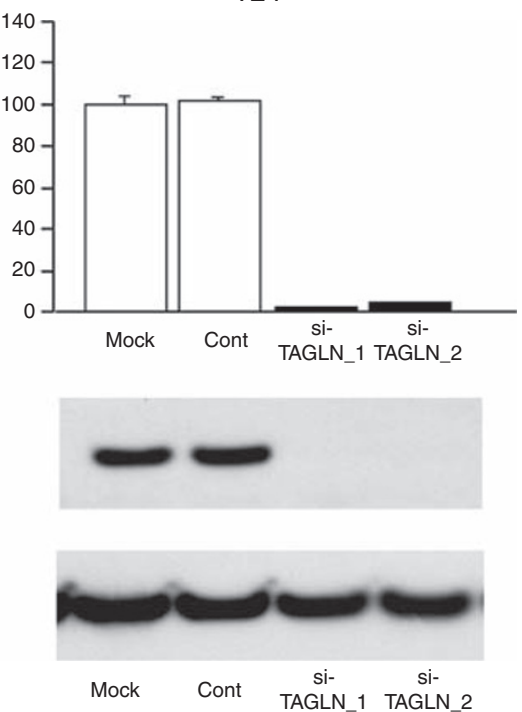

B

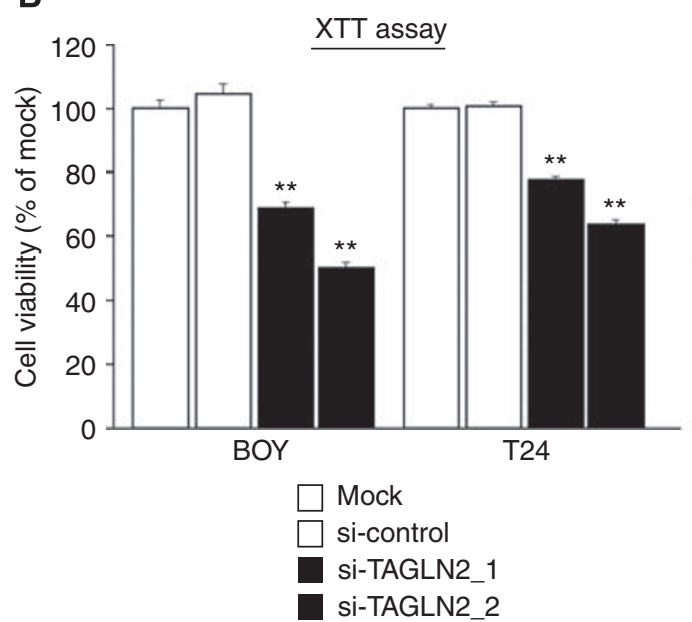

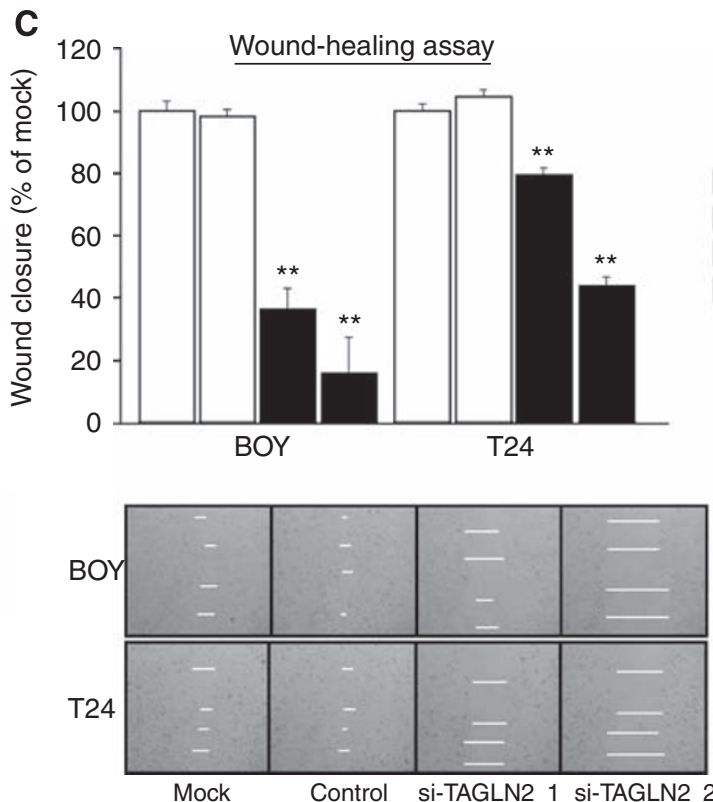

Figure 6 (A, upper) TAGLN2 mRNA expression after $24 \mathrm{~h}$ of transfection with $10 \mathrm{nM}$ of si-TAGLN2. TAGLN2 mRNA expression was repressed in si-TAGLN2 transfectants. (A, lower) TAGLN2 protein expression after $72 \mathrm{~h}$ of transfection of the siRNAs. GAPDH was used a loading control. (B - D) TAGLN2-knockdown effects on BC cell viability by si-RNA. (B) Cell proliferation determined by the XTT assay; (C) cell migration activity determined by the wound healing assay; and (D) cell invasion activity determined by the matrigel invasion assay in BOY and T24 cell lines transfected with si-TAGLN2. $* P<0.0005$; $* * P<0.0001$. (E) Apoptosis assay determined by flow cytometry. Early apoptotic cells can be seen in the bottom right quadrant and late are in the upper right. The normalised ratio of the apoptosis assay is shown in the histogram. ${ }^{*} * P<0.000 \mathrm{I}$. 

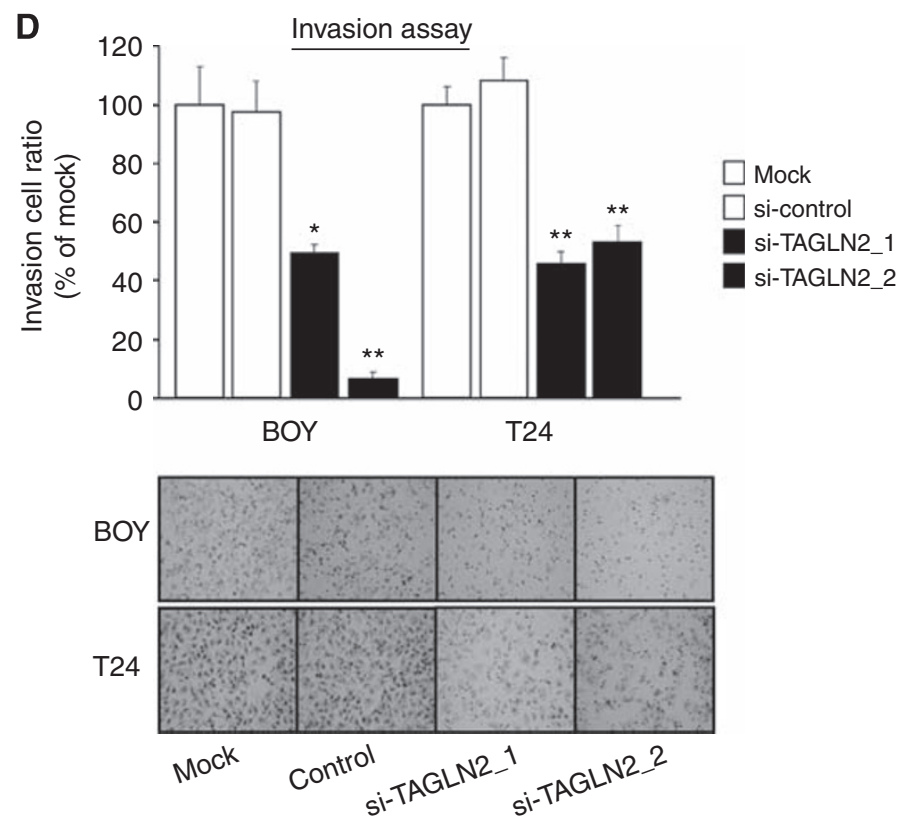

$\mathbf{E}$
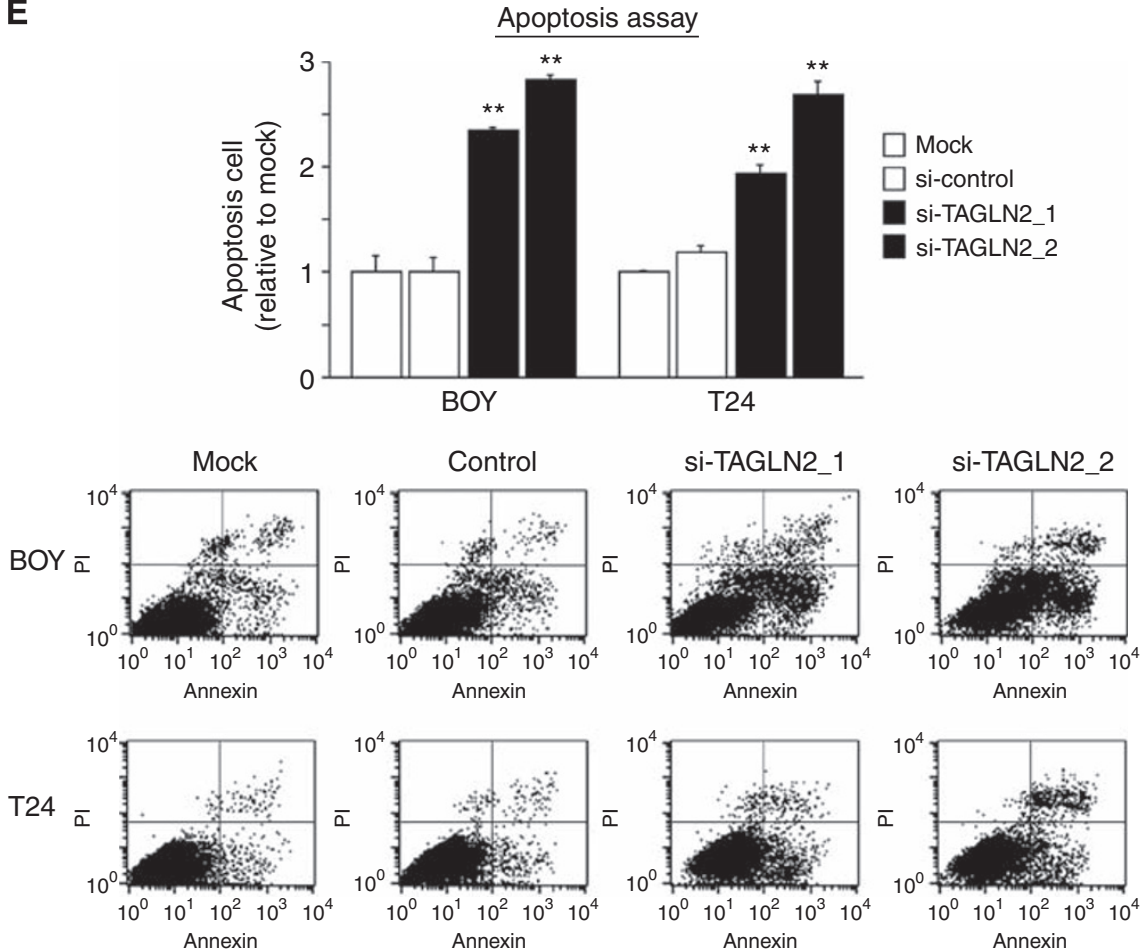

Figure 6 Continued.

significant correlations between the expression scores and tumour grade/metastasis ( $P=0.0148$ and $P=0.0145$, respectively; Table 3$)$.

\section{DISCUSSION}

In this study, we identified 17 downregulated miRNAs that survived after three different normalisation methods. Among them, we tested $m i R-133 a, m i R-204, m i R-1, m i R-139-5 p$, and $m i R-370$, which were the top five downregulated miRNAs. Investigators had demonstrated that $m i R-204$ was a tumoursuppressive miRNA in head and neck tumour (Lee et al, 2010);
miR-139-5p was downregulated in endometrial serous adenocarcinoma (Hiroki et al, 2010); and miR-370 expression was silenced by promoter hypermethylation in malignant human cholangiocytes (Meng et al, 2008). The expression levels of the five miRNAs were indeed downregulated in BC specimens as well as in $\mathrm{BC}$ cell lines. However, we found typical tumour-suppressive effects in miR-1- and miR-133a-transfected BC cell lines, and these miRNAs were plausible to be critical for BC development.

The $m i R-1$ and $m i R-133$ are cardiac and skeletal muscle-specific, bicistronic miRNAs transcriptionally controlled by some major regulators of muscle differentiation (Chen et al, 2006; Williams et al, 2009). These miRNAs have been reported to be 
A
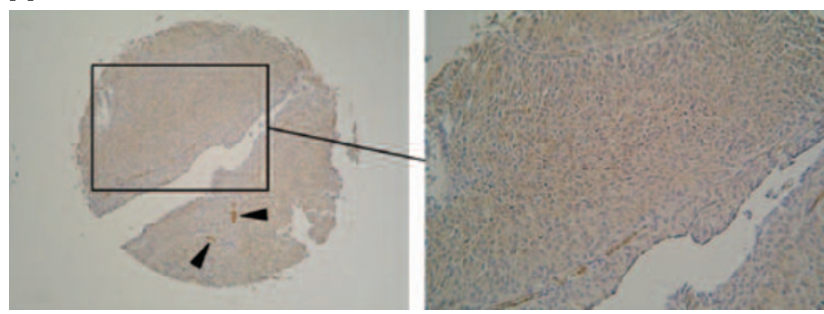

B
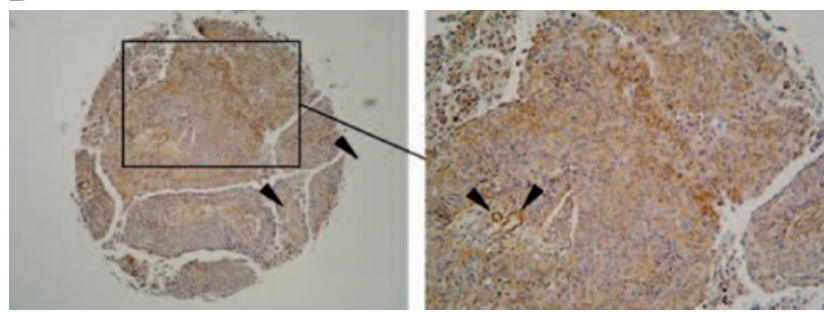

C
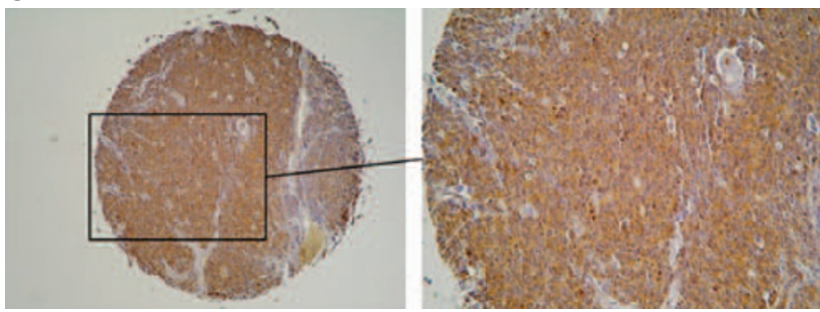

D
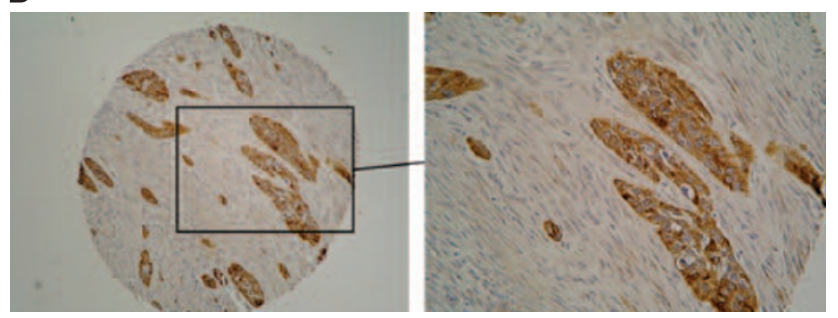

E

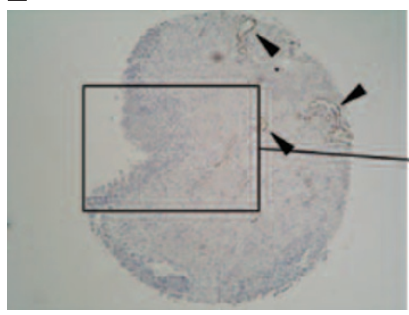

$\times 100$

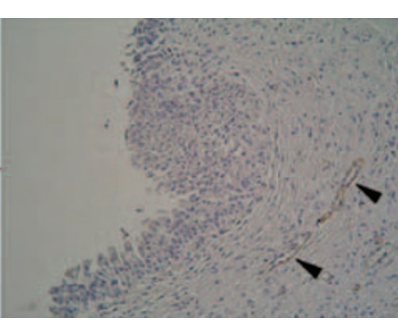

$\times 200$
Figure 7 Immunohistochemical staining of TAGLN2 in tissue specimens. (A) Positively stained tumour lesion (Grade I, T2bNOM0); (B) positively stained tumour lesion (Grade 2, T3NOMO); (C) positively stained tumour lesion (Grade 3, T2NOM0); (D) positive staining in metastatic BC cells of metastatic region (Grade 3); (E) negative staining in normal urocustis tissue. (A-D) Positive staining in tumour cells: weak $(\mathbf{A})$, moderate $(\mathbf{B})$, and strong $(\mathbf{C}, \mathbf{D})$. Some microvessel walls also stained positive for TAGLN2 (A, B, E arrowheads).

downregulated in human malignancies (Datta et al, 2008; Nasser et al, 2008; Yan et al, 2009; Uchida et al, 2010; Chiyomaru et al, 2010a). Ectopic expression of $m i R-1$ in HCC, lung cancer, prostate cancer, and rhabdomyosarcoma inhibited tumour cell growth (Ambs et al, 2008; Datta et al, 2008; Nasser et al, 2008; Yan et al,
Table 3 Relationships between TAGLN2 expression and clinicopathological factors in tissue microarray

\begin{tabular}{|c|c|c|c|c|c|}
\hline \multirow[b]{2}{*}{ Characteristics } & \multirow[b]{2}{*}{$n$} & \multicolumn{3}{|c|}{ TAGLN2 expression (score) } & \multirow[b]{2}{*}{$P$-values } \\
\hline & & $\begin{array}{l}\text { Low } \\
(0-2)\end{array}$ & $\begin{array}{l}\text { Moderate } \\
\text { (3 to } 4)\end{array}$ & $\begin{array}{c}\text { High } \\
\text { (5 to 6) }\end{array}$ & \\
\hline \multicolumn{6}{|c|}{ Normal and BC tissue } \\
\hline Normal & 8 & 8 & 0 & 0 & \multirow[t]{2}{*}{0.0202} \\
\hline Cancer & 47 & 22 & 20 & 5 & \\
\hline \multicolumn{6}{|l|}{ Age at presentation } \\
\hline$>65$ years & 17 & 9 & 6 & 2 & \multirow{2}{*}{0.7499} \\
\hline$\leqslant 65$ years & 30 & 13 & 14 & 3 & \\
\hline \multicolumn{6}{|l|}{ Sex } \\
\hline Male & 38 & 17 & 18 & 3 & \multirow{2}{*}{0.2635} \\
\hline Female & 9 & 5 & 2 & 2 & \\
\hline \multicolumn{6}{|l|}{ Histological grade } \\
\hline $\mathrm{G} 1+\mathrm{G} 2$ & 28 & 14 & 14 & 0 & \multirow[t]{2}{*}{0.0148} \\
\hline G3 & 19 & 6 & 8 & 5 & \\
\hline \multicolumn{6}{|l|}{ Tumour status } \\
\hline TI & 10 & 5 & 4 & I & \multirow[t]{3}{*}{0.9536} \\
\hline $\mathrm{T} 2+\mathrm{T} 3+\mathrm{T} 4$ & 28 & 15 & 11 & 2 & \\
\hline Unknown & 9 & & & & \\
\hline \multicolumn{6}{|l|}{ LN metastasis } \\
\hline No & 40 & 50 & 17 & 3 & \multirow[t]{3}{*}{0.5195} \\
\hline $\mathrm{NI}$ & I & 0 & 1 & 0 & \\
\hline Unknown & 6 & & & & \\
\hline \multicolumn{6}{|l|}{ Distant metastasis } \\
\hline MO & 43 & 22 & 18 & 3 & \multirow[t]{2}{*}{0.0145} \\
\hline $\mathrm{MI}$ & 4 & 0 & 2 & 2 & \\
\hline
\end{tabular}

Abbreviations: TAGLN2 = transgelin 2; $B C=$ bladder cancer; $L N=$ lymph node

2009). However, the function of $m i R-1$ in $\mathrm{BC}$ remains to be elucidated. MiR-1 had an important role in the regulation of apoptosis, which is involved in post-transcriptional repression of BCL2 in cardiomyocyte (Tang et al, 2009). In cancer research fields, ectopic miR-1 induced apoptosis through enhanced activation of caspases 3 and 7, cleavage of their substrate PARP-1, and depletion of antiapoptotic Mcl-1 in lung cancer cells (Nasser et al, 2008). Consistent with previous studies, re-expression of $m i R-1$ in $\mathrm{BC}$ cell lines resulted in induction of apoptosis and reduced cell viability in this study. Regarding $m i R-133 a$, previous studies demonstrated that its expression was downregulated in pancreatic ductal adenocarcinoma, oesophageal squamous cell carcinoma, rhabdomyosarcoma, colorectal cancer, and squamous cell carcinoma of the tongue (Bandrés et al, 2006; Szafranska et al, 2007; Wong et al, 2008a, b; Arndt et al, 2009; Yan et al, 2009; Kano et al, 2010). MiR-133a inhibited proliferation and induced apoptosis and directly bound to pyruvate kinase type M2 expression, which are potent oncogenes (Wong et al, 2008b). However, there has been no study concerning genes targeted by both $m i R-1$ and $m i R-133 a$, which are clustered on the same chromosomal loci in human malignancies. In BC, we have reported that $m i R-133 a$ had a critical role in regulating oncogenic FSCN1, LASP1, and GSTP1 (Uchida et al, 2010; Chiyomaru et al, 2010a, b) and have demonstrated for the first time that LASP1 was the target of $m i R-1 / m i R-133 a$ cluster (Chiyomaru et al, 2010b). In this study, the TAGLN2 gene was found to be another target of the $m i R-1 / m i R-133 a$ cluster. It is plausible that the $m i R-1 / m i R-133 a$ cluster may have important roles as tumour suppressors through downregulating these oncogenic genes. However, we found no simultaneous effect of cell viability inhibition by $m i R-1$ and $m i R-133 a$ co-transfection, suggesting that each miRNA may strongly repress same target 
genes and no additional effect might be caused by the other miRNA. Further investigations are necessary to elucidate the simultaneous effect of the $m i R-1 / m i R-133 a$ cluster. Our data suggest that retrieved expression of $m i R-1 / m i R-133 a$ clusters could be a new therapeutic strategy for $\mathrm{BC}$.

TAGLN2 contains a conserved actin-binding domain also known as the calponin (a calcium-binding protein) homologue domain. TAGLN and TAGLN3 are homologues of TAGLN2, and TAGLN3 is a novel neuron-specific protein and has not been reported in cancer (Ito et al, 2005). The protein encoded by the TAGLN gene is an actin-binding protein like TAGLN2, found in fibroblasts and smooth muscle. Overexpression of the TAGLN protein has been observed in carcinomas of the stomach, liver, and oesophagus (Rho et al, 2009). Although the function of TAGLN2 is unknown, there have been a number of reports concerning the relationship between TAGLN2 expression and tumourigenesis (Chen et al, 2005; Shi et al, 2005; Huang et al, 2006; Rho et al, 2009; Zhang et al, 2010). Overexpression of TAGLN2 was observed in HCC and pancreatic cancer (Chen et al, 2005; Shi et al, 2005; Huang et al, 2006). Zhang et al (2010) demonstrated that increased TAGLN2 expression was correlated with lymph node metastasis, distant metastasis, and the TNM classification in colorectal cancer. We also found a significant correlation of TAGLN2 expression with metastasis region and tumour grade despite of no correlation with tumour stage. Our tissue microarray included no Ta tumour and only four metastasis-positive patients. Studies for larger number of samples with balanced pathological background are needed to elucidate the precise correlation between TAGLN2 expression and clinicopathological parameters. These studies have implied that TAGLN2 may represent a potential tumour biomarker. We found that cell viability was markedly decreased in TAGLN2 knockdown cells by inducing apoptosis, which suggests that this molecule may have oncogenic function. However, it is still unknown how TAGLN2, which is an actin-binding protein, interacts with apoptosis. Further examinations are necessary to elucidate this.

In summary, $m i R-1 / m i R-133 a$ clusters may function as tumour suppressors through repression of oncogenic TAGLN2 in BC. MiR-1/miR-133a transfection and TAGLN2 knockdown resulted in decreased BC cell viability and induction of apoptosis. Novel molecular networks provided by miRNAs may provide new insights into the underlying molecular mechanisms of BC.

\section{ACKNOWLEDGEMENTS}

This research was partially supported by the Ministry of Education, Science, Sports and Culture Grants-in-Aid for Scientific Research (B and C), 20390427 and 20591861, 2008. We thank Ms Mutsumi Miyazaki for her excellent laboratory assistance.

Supplementary Information accompanies the paper on British Journal of Cancer website (http://www.nature.com/bjc)

\section{REFERENCES}

Ambs S, Prueitt RL, Yi M, Hudson RS, Howe TM, Petrocca F, Wallace TA, Liu CG, Volinia S, Calin GA, Yfantis HG, Stephens RM, Croce CM (2008) Genomic profiling of microRNA and messenger RNA reveals deregulated microRNA expression in prostate cancer. Cancer Res 68: 6162-6170

Arndt GM, Dossey L, Cullen LM, Lai A, Druker R, Eisbacher M, Zhang C, Tran N, Fan H, Retzlaff K, Bittner A, Raponi M (2009) Characterization of global microRNA expression reveals oncogenic potential of miR-145 in metastatic colorectal cancer. BMC Cancer 9: 374

Bandrés E, Cubedo E, Agirre X, Malumbres R, Zárate R, Ramirez N, Abajo A, Navarro A, Moreno I, Monzó M, García-Foncillas J (2006) Identification by real-time PCR of 13 mature microRNAs differentially expressed in colorectal cancer and non-tumoural tissues. Mol Cancer 5: 29

Calin GA, Croce CM (2006) MicroRNA signatures in human cancers. Nat Rev Cancer 6: 857-866

Chen JF, Mandel EM, Thomson JM, Wu Q, Callis TE, Hammond SM, Conlon FL, Wang DZ (2006) The role of microRNA-1 and microRNA-133 in skeletal muscle proliferation and differentiation. Nat Genet 38: 228 - 233

Chen R, Yi EC, Donohoe S, Pan S, Eng J, Cooke K, Crispin DA, Lane Z, Goodlett DR, Bronner MP, Aebersold R, Brentnall TA (2005) Pancreatic cancer proteome: the proteins that underlie invasion, metastasis, and immunologic escape. Gastroenterology 129: 1187-1197

Childs G, Fazzari M, Kung G, Kawachi N, Brandwein-Gensler M, McLemore M, Chen Q, Burk RD, Smith RV, Prystowsky MB, Belbin TJ, Schlecht NF (2009) Low-level expression of microRNAs let-7d and miR-205 are prognostic markers of head and neck squamous cell carcinoma. Am J Pathol 174: 736-745

Chiyomaru T, Enokida H, Kawakami K, Tatarano S, Uchida Y, Kawahara K, Nishiyama K, Seki N, Nakagawa M (2010a) Functional role of LASP1 in cell viability and its regulation by microRNAs in bladder cancer. Urol Oncol (in press)

Chiyomaru T, Enokida H, Tatarano S, Kawahara K, Uchida Y, Nishiyama K, Fujimura L, Kikkawa N, Seki N, Nakagawa M (2010b) miR-145 and miR-133a function as tumour suppressors and directly regulate FSCN1 expression in bladder cancer. Br J Cancer 102: 883-891

Datta J, Kutay H, Nasser MW, Nuovo GJ, Wang B, Majumder S, Liu CG, Volinia S, Croce CM, Schmittgen TD, Ghoshal K, Jacob ST (2008) Methylation mediated silencing of microRNA-1 gene and its role in hepatocellular carcinogenesis. Cancer Res 68: 5049-5058

Di Leva G, Gasparini P, Piovan C, Ngankeu A, Garofalo M, Taccioli C, Iorio MV, Li M, Volinia S, Alder H, Nakamura T, Nuovo G, Liu Y,
Nephew KP, Croce CM (2010) MicroRNA cluster 221-222 and estrogen receptor alpha interactions in breast cancer. J Natl Cancer Inst 102: $706-721$

Filipowicz W, Bhattacharyya SN, Sonenberg N (2008) Mechanisms of post-transcriptional regulation by microRNAs: are the answers in sight? Nat Rev Genet 9: $102-114$

Hiroki E, Akahira J, Suzuki F, Nagase S, Ito K, Suzuki T, Sasano H, Yaegashi N (2010) Changes in microRNA expression levels correlate with clinicopathological features and prognoses in endometrial serous adenocarcinomas. Cancer Sci 101: 241-249

Huang J, Sheng HH, Shen T, Hu YJ, Xiao HS, Zhang Q, Zhang QH, Han ZG (2006) Correlation between genomic DNA copy number alterations and transcriptional expression in hepatitis B virus associated hepatocellular carcinoma. FEBS Lett 580: 3571-3581

Ichimi T, Enokida H, Okuno Y, Kunimoto R, Chiyomaru T, Kawamoto K, Kawahara K, Toki K, Kawakami K, Nishiyama K, Tsujimoto G, Nakagawa M, Seki N (2009) Identification of novel microRNA targets based on microRNA signatures in bladder cancer. Int J Cancer 125: 345-352

Ito M, Depaz I, Wilce P, Suzuki T, Niwa S, Matsumoto I (2005) Expression of human neuronal protein 22, a novel cytoskeleton-associated protein, was decreased in the anterior cingulate cortex of schizophrenia. Neurosci Lett 378: $125-130$

Jemal A, Siegel R, Xu J, Ward E (2010) Cancer statistics, 2010. CA Cancer J Clin 60: $277-300$

Kano M, Seki N, Kikkawa N, Fujimura L, Hoshino I, Akutsu Y, Chiyomaru T, Enokida H, Nakagawa M, Matsubara H (2010) miR-145, miR-133a and miR-133b: tumor suppressive miRNAs target FSCN1 in esophageal squamous cell carcinoma. Int J Cancer 127: 2804-2814

Lee Y, Yang X, Huang Y, Fan H, Zhang Q, Wu Y, Li J, Hasina R, Cheng C, Lingen MW, Gerstein MB, Weichselbaum RR, Xing HR, Lussier YA (2010) Network modeling identifies molecular functions targeted by miR-204 to suppress head and neck tumor metastasis. PLoS Comput Biol 6: e1000730

Lu J, Getz G, Miska EA, Alvarez-Saavedra E, Lamb J, Peck D, Sweet-Cordero A, Ebert BL, Mak RH, Ferrando AA, Downing JR, Jacks T, Horvitz HR, Golub TR (2005) MicroRNA expression profiles classify human cancers. Nature 435: $834-838$

Meng F, Wehbe-Janek H, Henson R, Smith H, Patel T (2008) Epigenetic regulation of microRNA-370 by interleukin- 6 in malignant human cholangiocytes. Oncogene 27: $378-386$ 
Nasser MW, Datta J, Nuovo G, Kutay H, Motiwala T, Majumder S, Wang B, Suster S, Jacob ST, Ghoshal K (2008) Down-regulation of micro-RNA-1 (miR-1) in lung cancer. Suppression of tumourigenic property of lung cancer cells and their sensitization to doxorubicin-induced apoptosis by miR-1. J Biol Chem 283: 33394-33405

Parkin DM, Bray F, Ferlay J, Pisani P (2005) Global cancer statistics, 2002. CA Cancer J Clin 55: 74-108

Qiu D, Katanoda K, Marugame T, Sobue T (2009) A Joinpoint regression analysis of long-term trends in cancer mortality in Japan (1958-2004). Int J Cancer Jan 124: $443-448$

Rho JH, Roehrl MH, Wang JY (2009) Tissue proteomics reveals differential and compartment-specific expression of the homologs transgelin and transgelin-2 in lung adenocarcinoma and its stroma. J Proteome Res 8: $5610-5618$

Ryan BM, Robles AI, Harris CC (2010) Genetic variation in microRNA networks: the implications for cancer research. Nat Rev Cancer 10: $389-402$

Shirodkar SP, Lokeshwar VB (2009) Potential new urinary markers in the early detection of bladder cancer. Curr Opin Urol 19: 488-493

Shi YY, Wang HC, Yin YH, Sun WS, Li Y, Zhang CQ, Wang Y, Wang S, Chen WF (2005) Identification and analysis of tumour-associated antigens in hepatocellular carcinoma. Br J Cancer 92: 929-934

Sobin LH, Wittekind C (2002) TNM Classification of Malignant Tumours. 6th edn. International Union Against Cancer (UICC). Wiley-Liss: New York. pp 199-202

Szafranska AE, Davison TS, John J, Cannon T, Sipos B, Maghnouj A, Labourier E, Hahn SA (2007) MicroRNA expression alterations are linked to tumorigenesis and non-neoplastic processes in pancreatic ductal adenocarcinoma. Oncogene 26: $4442-4452$

Tang Y, Zheng J, Sun Y, Wu Z, Liu Z, Huang G (2009) MicroRNA-1 regulates cardiomyocyte apoptosis by targeting Bcl-2. Int Heart J 50: $377-387$

Uchida Y, Chiyomaru T, Enokida H, Kawakami K, Tatarano S, Kawahara K, Nishiyama K, Seki N, Nakagawa M (2010) MiR-133a induces apoptosis through direct regulation of GSTP1 in bladder cancer cell lines. Urol Oncol (in press)

Williams AH, Liu N, van Rooij E, Olson EN (2009) MicroRNA control of muscle development and disease. Curr Opin Cell Biol 21: $461-469$

Wong TS, Liu XB, Chung-Wai Ho A, Po-Wing Yuen A, Wai-Man Ng R, Ignace Wei W (2008a) Identification of pyruvate kinase type M2 as potential oncoprotein in squamous cell carcinoma of tongue through microRNA profiling. Int $J$ Cancer 123: $251-257$

Wong TS, Liu XB, Wong BY, Ng RW, Yuen AP, Wei WI (2008b) Mature miR-184 as potential oncogenic microRNA of squamous cell carcinoma of tongue. Clin Cancer Res 14: 2588-2592

Yan D, Dong Xda E, Chen X, Wang L, Lu C, Wang J, Qu J, Tu L (2009) MicroRNA-1/206 targets c-Met and inhibits rhabdomyosarcoma development. J Biol Chem 284: 29596-29604

Zhang Y, Ye Y, Shen D, Jiang K, Zhang H, Sun W, Zhang J, Xu F, Cui Z, Wang S (2010) Identification of transgelin-2 as a biomarker of colorectal cancer by laser capture microdissection and quantitative proteome analysis. Cancer Sci 101: 523-529

Zhang ZW, An Y, Teng CB (2009) The roles of miR-17-92 cluster in mammal development and tumorigenesis. Yi Chuan 31: 1094-1100 